\title{
Clinical Efficacy of Corticosteroids in the Early Stages of Deterioration in COVID-19 Pneumonia
}

\author{
Zheng Liu* \\ Fang Shi \\ Jun-Xia Liu \\ Jia-Qi Liu \\ Jing Li \\ Qian Wang \\ Hui Wang \\ Chang-Lan Gao \\ Jian-Min Li \\ Dong-Fang Zhao* \\ 'Department of Respiratory Medicine, \\ The Petroleum Clinical Medical College \\ of Hebei Medical University, Langfang, \\ Hebei, 065000, People's Republic of \\ China; ${ }^{2}$ Schulich School of Medical and \\ Dentistry-Honour Specialization in \\ Interdisciplinary Medical Science and \\ Major in Pharmacology, Western \\ University, London, Ontario, Canada; \\ ${ }^{3}$ Department of Critical Care Medicine, \\ Langfang Fourth Hospital, Langfang, \\ Hebei, People's Republic of China \\ *These authors contributed equally to \\ this work
}

Background: The World Health Organization (WHO) strongly suggests using corticosteroids in patients with severe coronavirus disease 2019 (COVID-19). Similarly, a large randomized controlled clinical trial (RCT) in the UK found that dexamethasone effectively reduced the mortality rate in severe COVID-19 patients. However, the safety profile of corticosteroids has been a controversial area of study.

Case Description: A case of a COVID-19 patient is described and the clinical characteristics are observed as the mildly symptomatic patient progresses into a critically ill patient and during their dramatic improvement with corticosteroid therapy in the early stage of the deterioration process with COVID-19 pneumonia.

Conclusion: The most suitable timing and dosage for the use of corticosteroids to maximize its effect during the worsening of COVID-19 pneumonia are discussed. One of the main pathophysiological hypotheses for severe COVID-19 patients is related to cytokine storm and virus load, which can be effectively treated with corticosteroid therapy.

Keywords: COVID-19 pneumonia, cytokine storm, corticosteroids, clinical characteristics

\section{Introduction}

Coronavirus disease 2019 (COVID-19) is an infectious viral disease caused by a newly discovered coronavirus, namely severe acute respiratory syndrome coronavirus-2 (SARS-CoV-2). ${ }^{1}$ COVID-19 is highly infectious and can lead to fatal comorbidities, specifically acute respiratory distress syndrome (ARDS). It has been noted that the elevation of various proinflammatory cytokines is present in a proportion of patients infected with SARS-CoV-2, suggesting the possible existence of a cytokine storm. ${ }^{2}$ In addition, patients requiring intensive care unit (ICU) admission showed higher concentrations of particular cytokines compared with those not requiring ICU admission, indicating that the levels of proinflammatory cytokines are associated with disease severity. ${ }^{3,4}$ Therefore, it is essential to develop an effective treatment strategy to control the spread of the virus and prevent the development of a cytokine storm. Corticosteroids can be used to suppress the cytokine storm and have been used in some patients. ${ }^{5-8}$ In the recent RECOVERY trial, the effectiveness of dexamethasone was evaluated, and reduced 28-day mortality in patients requiring oxygen therapy or mechanical ventilation was shown. ${ }^{9}$ On the other hand, corticosteroids did not provide a survival benefit for patients with Middle East respiratory syndrome and ARDS; ${ }^{10}$ rather, they prolonged virus clearance time. Nevertheless, based on a moderate certainty of evidence, systemic corticosteroid usage is strongly recommended over not using them to treat patients with severe and critical COVID-19. ${ }^{11}$ In another study, low-dose (not high) corticosteroids
Correspondence: Zheng Liu; Dong-Fang Zhao

Department of Respiratory Medicine, The Petroleum Clinical Medical College of Hebei Medical University, Langfang, Hebei, 065000, People's Republic of China Tel +86 316 20778I4; +863162077345 Email zheng106drsun@163.com; dongfang06_walker@2I cn.com 
reduced mortality in people with $\mathrm{ARDS},{ }^{12}$ suggesting that dosage may be an important covariate in data analyses. As a result, questions related to the timing and dosage of corticosteroids administration are discussed.

\section{Case Description}

On February 8, 2020, a 52-year-old Chinese woman reported fever and coughing symptoms for three days. This female patient had an eight-year history of hypertension and coronary heart disease. Her daily medication included one $30 \mathrm{mg}$ nifedipine extended-release tablet and one $100 \mathrm{mg}$ Bayaspirin tablet, both taken orally. She denied a history of recent travel. However, she was in close contact with her son, who had been infected with COVID-19 five days previously. She was immediately isolated in an airborne infection isolation room, as her throat swab tested positive for SARS-CoV-2 on a realtime reverse transcriptase-polymerase chain reaction test.

Clinically, the body temperature, oxygen saturation $\left(\mathrm{SaO}_{2}\right)$ on room air, and respiratory rate of the patient were $38.6^{\circ} \mathrm{C}, 91 \%$, and 20 breaths $/ \mathrm{min}$, respectively. On examination, her lungs were clear on auscultation. Laboratory investigations revealed a white blood cell count of $5.3 \times 10^{9} / \mathrm{L}$, a lymphocyte count of $1.12 \times 10^{9} /$ $\mathrm{L}$, a hemoglobin level of $12.6 \mathrm{~g} / \mathrm{dL}$, and a platelet count of $153 \times 10^{9} / \mathrm{L}$. C-reactive protein was elevated, at $75.6 \mathrm{mg} / \mathrm{L}$ (normal value $\leq 7.5 \mathrm{mg} / \mathrm{L}$ ), and procalcitonin was $<0.1 \mathrm{ng}$ / $\mathrm{mL}$ (normal value $\leq 0.5 \mathrm{ng} / \mathrm{mL}$ ).

On admission, blood glucose was $11.28 \mathrm{mmol} / \mathrm{L}$, and urinalysis showed glycosuria +++ and ketone bodies \pm , demonstrating abnormalities from the normal range. Her serum lactate, liver function, and renal function tests were normal. However, computed tomography (CT) of her chest showed subtle ground-glass opacities or consolidation in both lungs without pleural effusion (Figure 1: A1-A2). The patient was treated with lopinavir/ritonavir, inhaled aerosolized recombinant human interferon, and traditional Chinese medicine.

Within 48 hours of presentation, the patient experienced increasing difficulty breathing, with severe dry cough. Examination showed a body temperature of $38.1^{\circ} \mathrm{C}$, respiratory rate of 34 breaths $/ \mathrm{min}$, and $\mathrm{SaO} 2$ of $86 \%$ on $5 \mathrm{~L} / \mathrm{min}$ oxygen by face mask.

A repeat chest CT showed the rapid development of bilateral diffuse ground-glass opacities or consolidation (Figure 1: B1-B2). Considering the possibility of a cytokine storm, methylprednisolone $40 \mathrm{mg}$ /day was administered intravenously for five days. The patient received high-flow-oxygen therapy (flow rate of $60 \mathrm{~L} /$ min, oxygen concentration $65 \%$ ) and maintained $\mathrm{SaO}_{2}$ at $88 \%$. Bedside ultrasonography revealed a left ventricular ejection fraction of $50 \%$ and ventricular wall motion normality. Kerley B lines appeared on both of the dorsal lungs. In response, $20 \mathrm{mg}$ of furosemide was given intravenously. Meanwhile, the patient's activity level was reduced, and an indwelling urinary catheter was sited. After 60 hours of treatment, the patient's blood pressure was $78 / 50 \mathrm{mmHg}$, and she was sweating profusely. A $250 \mathrm{~mL}$ bolus of $0.9 \%$ saline was infused rapidly (over $10 \mathrm{~min}$ ) without significant improvement. The vasoactive drug dopamine was then given to maintain blood pressure at approximately $95 / 60 \mathrm{mmHg}$. When the oxygen concentration was decreased to about $70 \%$, the patient's $\mathrm{SaO}_{2}$ fluctuated between $96 \%$ and $99 \%$. Blood levels of troponin, amino-terminal pro-brain natriuretic peptide, and D-dimer were all normal. The oxygenation index was $122 \mathrm{mmHg}$. Thus, she was intubated and initiated on mechanical ventilation.

Despite deep sedation, significant ventilator dyssynchrony was initiated to maintain the lung's protective ventilation. The patient was supported with volumecontrolled ventilation: tidal volume $350 \mathrm{~mL}, \mathrm{FiO}_{2} 0.8$, PEEP $10 \mathrm{cmH}_{2} \mathrm{O}$, and a respiratory rate of 20 breaths/ min with a platform pressure of $20 \mathrm{cmH}_{2} \mathrm{O}$. Arterial blood gas analysis showed a $\mathrm{pH}$ of 7.43, a $\mathrm{CO}_{2}$ partial pressure of $38.8 \mathrm{mmHg}$, and an $\mathrm{O}_{2}$ partial pressure of 158 $\mathrm{mmHg}$. The value of $\mathrm{FiO}_{2}$ was adjusted to 0.55 , and she did not require prone ventilation.

After five days of mechanical ventilation, normothermia, and oxygenation, the appearance of the ground glass opacities on the chest X-ray improved, the results of all bacterial cultures were negative, and she was successfully extubated.

On the $15^{\text {th }}$ day of admission, a pharyngeal swab for COVID-19 was negative (Table 1).

On follow-up after discharge, the patient had no complications, and chest $\mathrm{CT}$ appearances continued to improve at one, three, and six months (Figure 1).

This study was conducted in accordance with the Declaration of Helsinki and approved by the Ethics Committee of the Petroleum Clinical Medical College of Hebei Medical University. The consent from the patient for the publication of the case was obtained.

\section{Discussion}

According to the data analysis by the World Health Organization (WHO), China had approximately 17,000 
A

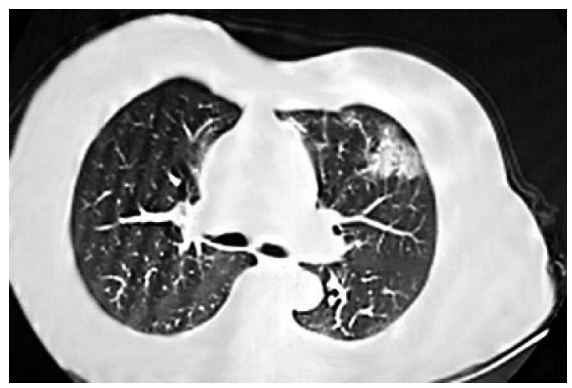

B
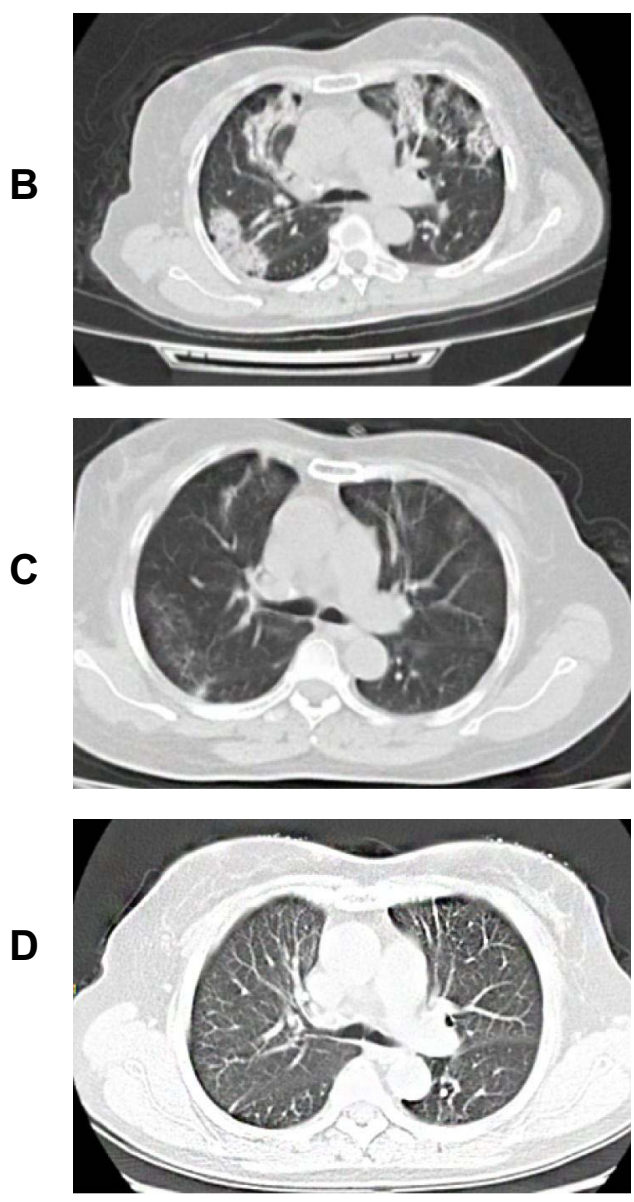
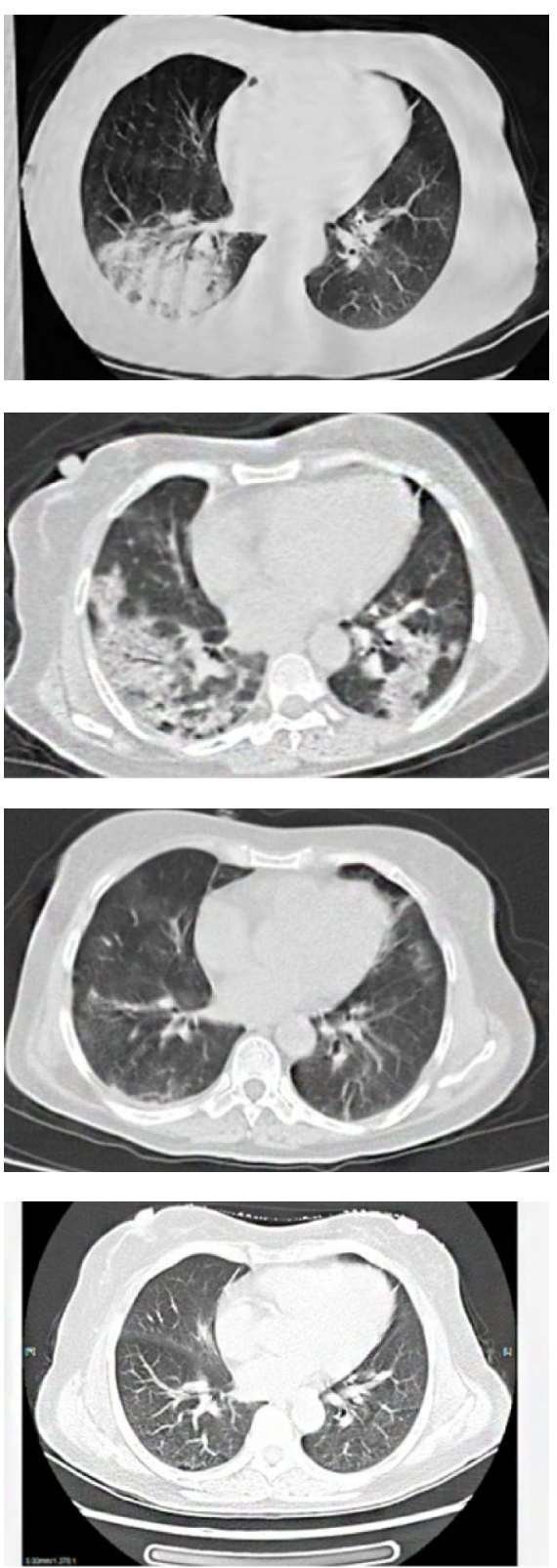

Figure I Chest CT images of a 52-year-old woman with COVID-19 pneumonia. Chest CT images (AI and A2) show patchy ground glass opacities with alveolar consolidation in dependent segments of both lungs with an asymmetric distribution. Three days later, CT images (BI and B2) revealed a marked increase in lesions. CT images (CI and C2) on day eight, after five days of corticosteroid use, showed a significant decrease in lesions. CT images (DI and D2), after six months of follow-up, are normal.

COVID-19 patients when SARS-CoV-2 was first identified. Among those patients, $80 \%$ had mild disease, $15 \%$ had severe disease, and 3\% were critically ill. Overall, the mortality rate was $2 \%$. However, $50 \%$ of the mortality was associated with critically ill patients. ${ }^{1,5,8}$ Thus, we intended to pay more attention to the characteristics and intervention of patients during the transition process where mildly infected patients become severely infected patients. In our patient, we described the clinical course of COVID-
19 infection that rapidly developed into ARDS requiring intubation. This case highlights that at-risk patients can be promptly identified and closely monitored.

\section{Theories of "Viral Load," "Cytokine Storm," and Clinical Manifestations}

According to Zhou's paper in The Lancet, ${ }^{7}$ inflammation and the immune response are the main mechanisms that result in viruses getting "killed." The inflammatory 


\begin{tabular}{|c|c|c|c|c|c|c|c|c|c|c|c|c|c|c|c|c|}
\hline 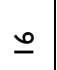 & \pm & $\stackrel{n}{n}$ & & & $\neq$ & $\stackrel{n}{\stackrel{n}{m}}$ & $\hat{o}$ & in & $\stackrel{\dot{m}}{m}$ & $\frac{m}{0}$ & & & $\hat{i}$ & సें & & \\
\hline$\underline{\underline{n}}$ & $\underline{m}$ & 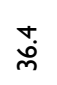 & $\stackrel{n}{n}{ }_{0}$ & 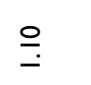 & $\bar{\gamma}$ & $\overline{\text { j }}$ & $\stackrel{0}{\circ}$ & 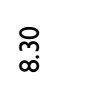 & $\frac{m}{m}$ & $\frac{0}{0}$ & 总 & $\begin{array}{l}\text { త্ } \\
\text { I }\end{array}$ & & ஓें & & \\
\hline \pm & $\simeq$ & tे. & $\stackrel{\infty}{\stackrel{\infty}{\infty}}$ & $\cong$ & & & & & & & & & & ฌें & & \\
\hline$\underline{m}$ & $=$ & $\stackrel{\circ}{\dot{m}}$ & $\underset{\infty}{\stackrel{\omega}{\infty}}$ & 目 & $\mathcal{F}$ & $\hat{\text { i }}$ & $\stackrel{\sim}{\dot{\Psi}}$ & $\stackrel{+}{0}$ & $\underset{\text { స్ }}{ }$ & $\frac{\circ}{0}$ & ले & & $\stackrel{\sigma}{\tilde{m}}$ & స్ & 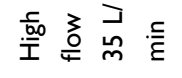 & \\
\hline$\simeq$ & 으 & $\stackrel{\dot{\omega}}{\dot{m}}$ & $\stackrel{\circ}{\underline{i}}$ & $\stackrel{m}{=}$ & $\stackrel{\infty}{m}$ & 离 & $\stackrel{\infty}{\alpha}$ & in & $\begin{array}{l}\hat{\rho} \\
\dot{m}\end{array}$ & $\frac{0}{0}$ & 心్ & & $\stackrel{\stackrel{n}{m}}{n}$ & ১̊ & & \\
\hline$=$ & $a$ & iे & & & & & & & & & & & $\stackrel{\sim}{+}$ & o̊ & 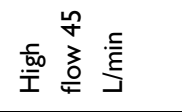 & \\
\hline 으 & $\infty$ & $\stackrel{n}{\stackrel{n}{\circ}}$ & $\stackrel{t}{i}$ & ğ & m̊ & $\begin{array}{l}\stackrel{a}{\mu} \\
\dot{m}\end{array}$ & $\begin{array}{l}\stackrel{2}{\infty} \\
\infty\end{array}$ & & $\stackrel{\infty}{m}$ & $\frac{n}{0}$ & 志 & & & ڤํ & & \\
\hline$\sigma$ & $\wedge$ & 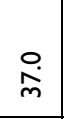 & $\stackrel{+}{\stackrel{+}{+}}$ & นุे & & & & & & & & & 으 & ○ें & 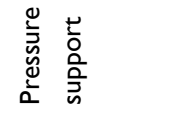 & \\
\hline$\infty$ & 0 & $\begin{array}{l}\infty \\
\dot{m} \\
\dot{m}\end{array}$ & 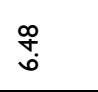 & $\stackrel{\infty}{0}$ & $\approx$ & $\bar{m}$ & $\begin{array}{l}\stackrel{0}{\mathfrak{o}} \\
\underline{\underline{i n}}\end{array}$ & $\overline{\grave{n}}$ & $\stackrel{m}{\beta}$ & $\frac{a}{0}$ & $\stackrel{\infty}{o}$ & $\begin{array}{l}\infty \\
\stackrel{\infty}{N} \\
\end{array}$ & 으 & ఫे & & 多 \\
\hline r & n & $\hat{m}$ & $\stackrel{t}{\stackrel{N}{n}}$ & $\bar{i}$ & & & & & & & & & & 。ㅇ & 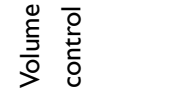 & 多 \\
\hline 0 & $\sigma$ & 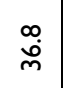 & 웅 & นึ้ & సे & $\stackrel{n}{m}$ & $\frac{a}{i}$ & & $\stackrel{m}{i}$ & $\frac{0}{0}$ & $\frac{\circ}{\sigma}$ & 芦 & m. & ळें & & \\
\hline in & $m$ & $\stackrel{\circ}{\dot{m}}$ & & & & & & & & & & & & ڤํํำ & 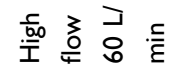 & \\
\hline$\sigma$ & N & $\stackrel{0}{\infty}$ & & & & & & & & & & & & $\vec{n}$ & & \\
\hline$m$ & - & 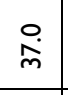 & $\stackrel{\text { ڤ̊ }}{m}$ & $\cong$ & $\bar{N}$ & $\hat{\dot{q}}$ & $\stackrel{\stackrel{\infty}{̣}}{=}$ & $\begin{array}{l}8 \\
\text { ㅇ. } \\
\text { م }\end{array}$ & $\stackrel{0}{\bar{\sigma}}$ & $\overline{0}$ & 今 & & & $\vec{N}$ & & \\
\hline 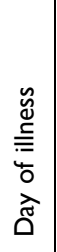 & 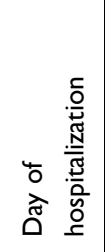 & 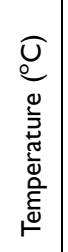 & 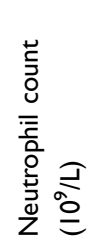 & 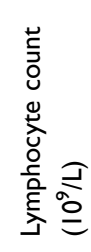 & 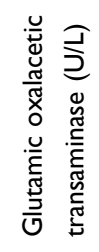 & 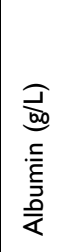 & 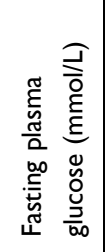 & 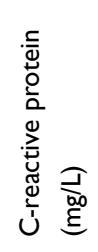 & 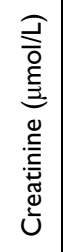 & 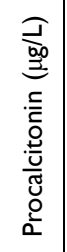 & 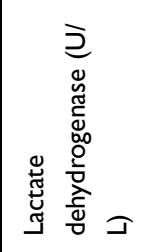 & 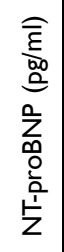 & 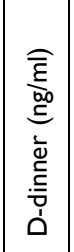 & 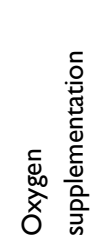 & 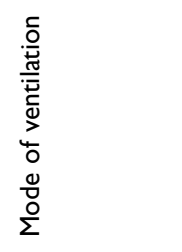 & 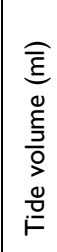 \\
\hline
\end{tabular}




\begin{tabular}{|c|c|c|c|c|c|c|c|c|c|c|c|c|c|}
\hline & & & & & & & & & & & & & 오 \\
\hline & & & & & & & & 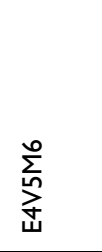 & 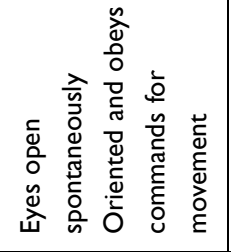 & 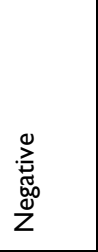 & & & ధి \\
\hline & & & $\bar{n}$ & & & & & & & 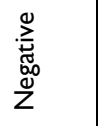 & $\begin{array}{l}\overline{0} \\
\frac{0}{0} \\
\frac{0}{\dot{\alpha}}\end{array}$ & & ○ \\
\hline & & & $\bar{m}$ & & & & & & & & & & $\underline{\circ}$ \\
\hline & & & ָี & & & & & $\sum_{\Psi}^{\infty}$ & & & & & $\stackrel{\text { }}{\sim}$ \\
\hline$\simeq$ & & in & క్ర & 으 & $m$ & & 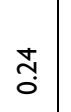 & & & & $\begin{array}{l}\overline{0} \\
\frac{0}{0} \\
\frac{0}{2}\end{array}$ & & 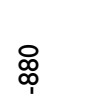 \\
\hline$\underline{\underline{n}}$ & & $\infty$ & 旤 & 움 & 0 & & $\stackrel{\text { m̃ }}{\circ}$ & $\sum_{4}^{\infty}$ & 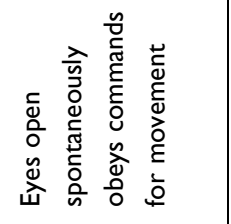 & & & 우 & ఫ్లి \\
\hline i & & 으 & ڤે & i & $m$ & - & & & & & $\begin{array}{l}\overline{0} \\
\frac{0}{90} \\
\frac{1}{\alpha}\end{array}$ & 우 & 요 \\
\hline & 요 & 으 & 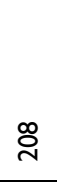 & i & $m$ & $\sim$ & & 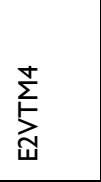 & 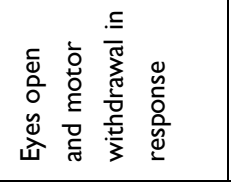 & & & 우 & $\stackrel{\infty}{1}$ \\
\hline & $\ddot{\sim}$ & 으 & 吉 & 요 & + & $m$ & & 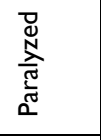 & & & $\begin{array}{l}\overline{0} \\
\frac{0}{00} \\
\frac{1}{4}\end{array}$ & q & 弚 \\
\hline & & & ஃ & & & & & & & & & & $\stackrel{\circ}{\stackrel{\circ}{\circ}}$ \\
\hline & & & $\stackrel{\tilde{m}}{\underline{n}}$ & & & & & & & & & & $\begin{array}{l}\stackrel{\circ}{\stackrel{\leftrightarrow}{m}} \\
\frac{1}{1}\end{array}$ \\
\hline & & & $\stackrel{\tilde{q}}{\underline{y}}$ & & & & & & & 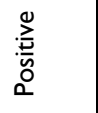 & & 우 & ষ্ণ \\
\hline & & & $\stackrel{\varrho}{\varrho}$ & & & & & & & $\begin{array}{l}\stackrel{0}{2} \\
\stackrel{\bar{y}}{0} \\
0\end{array}$ & 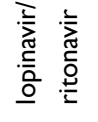 & & ర్రి \\
\hline 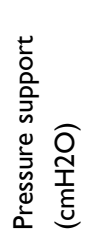 & 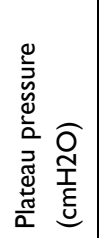 & 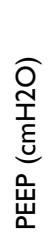 & 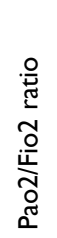 & 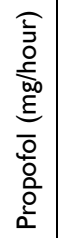 & 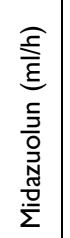 & 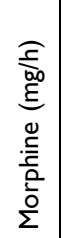 & 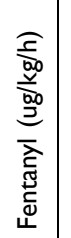 & 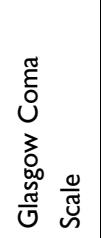 & 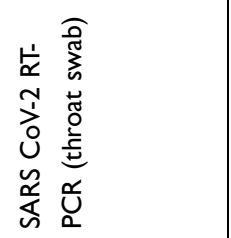 & 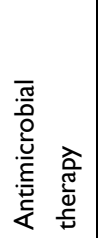 & 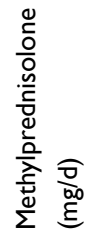 & 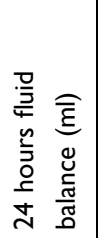 & 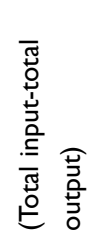 \\
\hline
\end{tabular}


response leads to a vicious cycle that continues to cascade and enlarges, producing a massive number of inflammatory mediators and cytokines. Cytokine storm is induced when the immune response and high viral load occur simultaneously.

Hans Bösmüller et $\mathrm{al}^{13}$ analyzed the clinical process from a pathological perspective and suggested that pulmonary COVID-19 can be subdivided into four main morphological stages, including (1) an early stage (day 0-1) with edema, incipient epithelial damage, and capillaritis/endothelialitis, (2) a stage of exudative diffuse alveolar damage (DAD) (days 1-7), and (3) an organizing (1 to several weeks) and (4) fibrotic stage of DAD (weeks to months). The early disease stage of severe COVID-19 is characterized by virally induced hyperactivation of the innate immune system, leading to the formation of a cytokine storm. The occurrence of a cytokine storm interferes with type I interferon antiviral response, subsequently resulting in endothelial and vascular damages, ultimately leading to hypercoagulability and thromboembolic events.

The clinical difference between SARS and SARS-CoV -2 is that SARS-CoV-2 patients experience a milder symptom of dyspnea relative to lung CT appearances. However, hypoxemia appears more consistent with CT imaging. Findings from many published clinical cases demonstrate that as the symptoms of SARS-CoV-2 worsen, the typical CT images show bilateral pulmonary parenchymal groundglass and consolidative pulmonary opacities, sometimes with a rounded morphology and a peripheral lung distribution. Lung involvement with a peripheral predominance was also seen in patients with SARS-CoV and MERS-CoV infections. The chest CT showed that the disease progressed with ground-glass opacities and consolidation, which is similar to that of SARS-CoV-2 infection. ${ }^{14}$

Based on our experience, clinicians should pay attention to the following factors: a persistent fever, progressive dyspnea, continuously declining oxygenation, progressively declining lymphocyte count, and rapid expansion in lung lesions, as shown on CT. Most importantly, the increase in ground-glass opacities (50\% increase in 48 hours) and consolidation should be carefully observed. ${ }^{15}$ Many scholars also paid attention to the ratio of neutrophils and lymphocytes, the continuous decline in CD4+ and CD8+ T cells, and the progressive increase in IL-6 and CRP. The symptoms described above, or the change in laboratory parameters and lung CT imaging, suggest worsening of the disease, and intervention treatments should be initiated as soon as possible.

\section{Corticosteroids and COVID-19}

The most common complication of COVID-19 is ARDS. The occurrence of ARDS in critically ill patients is as high as $67 \%$. When encountering the complex scenario of severely ill COVID-19 patients, a variety of protocols developed in various countries favor complementary treatments; for example, antiviral, inhaled aerosolized recombinant human interferon, and low-molecular-weight heparin. ${ }^{16}$ However, these treatments have had little effect.

Corticosteroid use is considered a potential treatment for ARDS due to its role in reducing hyperinflammation and fibrosis. Methylprednisolone shortened the period of invasive mechanical ventilation needed and lowered mortality in ARDS patients. ${ }^{17}$ A high number of observational studies and RCT on corticosteroids for COVID-19 suggest that administration of systemic corticosteroids demonstrate beneficial effects compared with routine care or placebo. The RECOVERY trial was the first to report that the use of dexamethasone, as opposed to standard care, reduced 28day mortality in patients requiring oxygen therapy or mechanical ventilation. ${ }^{18}$

\section{Appropriate Timing for the Use of Glucocorticoids in COVID-19 Patients}

The pathological manifestations of COVID-19 are mostly diffuse alveolar damage and fibrous mucus exudation with severe inflammatory lesions. Thus, critical care specialists suggest that glucocorticoid treatment is necessary to reduce or prevent the occurrence of ARDS. Clinically, some doctors use a low-to-moderate dose of glucocorticoids. The dose given depends on the rapid increase of imaging sites and the expansion of consolidation scope, and progressively worsening indicators of oxygenation. ${ }^{9,19}$

A cohort study conducted in Spain (https://doi.org/10. 21203/rs.3.rs-71610/vl) considered 48 hours of ICU admission as the critical point of glucocorticoid usage. They compared the clinical outcomes of patients treated with early corticosteroid therapy (before or within the first 48 hours of ICU admission) and patients that did not receive early corticosteroid therapy or had no corticosteroid therapy at all. Compared with the non-early corticosteroid treated group (40.6\%), patients who received early corticosteroid therapy $(30.3 \%)$ had significantly lower ICU mortality (HR 0.71, 95\% CI 0.57-0.89) and a higher 
number of ventilator-free days (mean difference 2.5 days, 95\% CI 1.3-3.8).

A recent meta-analysis of 12 studies was conducted to evaluate the effectiveness and safety of corticosteroid usage. In three studies, corticosteroids were started at diagnosis/ hospital admission. ${ }^{20-22}$ In other studies, ICU admission or respiratory deterioration were the indications to start. ${ }^{23,24}$

In contrast with the aforementioned study, our study focused more on mildly symptomatic patients who were progressing to become critically ill patients rather than the timing of ICU admission. Thus, we recommend considering the following parameters for the optimal timing of glucocorticoid usage in treating COVID-19 pneumonia: (1) continuous fever, (2) respiratory rate $>30$ breaths/min, (3) severe respiratory distress, (4) arterial oxygen saturation measured by pulse oximeter $(\mathrm{SpO} 2) \leq 93 \%$ on room air, (5) progressive decline in lymphocyte count, and (6) rapid expansion of lung lesions on CT. Any changes in the factors described above should be considered the initial sign of a cytokine storm and prompt early intervention with glucocorticoids.

\section{Clinical Dosage of Glucocorticoid Used in Patients with COVID-19 Pneumonia}

Reports showed that low-to-moderate doses of corticosteroids were also associated with reduced mortality in patients with viral pneumonia when the oxygenation index was lower than $300 \mathrm{mmHg} .{ }^{14}$ The WHO recommends the dosage of systemic corticosteroid therapy as follows: once-daily regimens of dexamethasone $6 \mathrm{mg}$ are equivalent to $160 \mathrm{mg}$ of hydrocortisone (eg, $50 \mathrm{mg}$ every 8 hours or $100 \mathrm{mg}$ every 12 hours), $40 \mathrm{mg}$ of prednisone, $32 \mathrm{mg}$ of methylprednisolone (eg, $8 \mathrm{mg}$ every 6 hours or $16 \mathrm{mg}$ every 12 hours). Duration: up to 7-10 days.

In the 44 studies, very diverse corticosteroid strategies were used. If reported $(\mathrm{n}=35)$, methylprednisolone was the most frequently prescribed $(\mathrm{n}=28) .^{20,25}$ Prednisone $(\mathrm{n}$ $=5)$, dexamethasone $(\mathrm{n}=5)$, and hydrocortisone $(\mathrm{n}=4)$ were also used, some in studies that allowed multiple corticosteroid regimens $(n=9)$.

Based on our own experience, continuously taking $0.75 \mathrm{mg} / \mathrm{kg}$ of methylprednisolone once or twice per day for five days may improve symptoms, especially with difficulty in breathing. The use of corticosteroids in the early stages of deterioration is essential, as it reduces the innate immune response caused by the cytokine storm, causing less damage to lung tissues. ${ }^{19}$
Other treatments are also required in the management of severe COVID-19; for example, humidified oxygen with a high-flow rate and high-flow volume in the early stage of the disease, ventilation in the supine position, moderate fluid restriction, convalescent plasma containing anti-COVID-19 antibodies, ${ }^{26}$ and subsequent mechanical ventilation and extracorporeal membrane oxygenation.

One limitation of our study is the lack of comparison between different types of corticosteroid treatments. Two types of corticosteroids were compared in a triple-blind $\mathrm{RCT}$, namely methylprednisolone ( $2 \mathrm{mg} / \mathrm{kg} / \mathrm{day}$; intervention group) and dexamethasone (6 mg/day; control group). It was found that methylprednisolone provides better clinical status than dexamethasone on day five and day 10 of admission and demonstrates less ventilator usage. Thus, the effectiveness of the drug may alter depending on the type of corticosteroid usage.

Another limitation relates to the dosing of corticosteroid therapy. Our study discussed the optimal dosage of corticosteroid therapy; however, the optimal dosage for each patient remains unknown. Further research should consider formulating a more detailed calculation for each patient, including the patient's weight as a factor in the dosing calculation.

In conclusion, we have examined the optimal timing and dosage of corticosteroid usage during the worsening process of COVID-19 pneumonia. Although controversy regarding corticosteroid treatment in COVID-19 still exists, many experts believe that it is reasonable to use corticosteroids for severely ill COVID-19 patients who have not yet developed ARDS. The decision on initial corticosteroid treatment should be based on the judgment of the clinical course and assessment of the treatment response.

\section{Consent to Publish}

The consent from the patient for the publication of the case was obtained.

\section{Funding}

This study was supported by clinical characteristics of sporadic and aggregated COVID-19 in Langfang [2020013002].

\section{Disclosure}

The authors report no conflicts of interest in this work. 


\section{References}

1. Huang C, Wang Y, Li X, et al. Clinical features of patients infected with 2019 novel coronavirus in Wuhan, China. Lancet. 2020;395:497-506. doi:10.1016/S0140-6736(20)30183-5

2. Ye Q, Wang B, Mao J. The pathogenesis and treatment of the 'cytokine storm' in COVID-19. J Inf Secur. 2020;80(6):607-613.

3. Zhang X, Tan Y, Ling Y, et al. Viral and host factors related to the clinical outcome of COVID-19. Nature. 2020;583(7816):437-440. doi:10.1038/s41586-020-2355-0

4. Sun Y, Dong Y, Wang L, et al. Characteristics and prognostic factors of disease severity in patients with COVID-19: the Beijing experience. $J$ Autoimmun. 2020;112:102473. doi:10.1016/j. jaut.2020.102473

5. Guan WJ, Ni ZY, Hu Y, et al. Clinical characteristics of coronavirus disease 2019 in China. N Engl J Med. 2020;382:1708-1720. doi:10.1056/NEJMoa2002032

6. Yang X, Yu Y, Xu J, et al. Clinical course and outcomes of critically ill patients with SARS-CoV-2 pneumonia in Wuhan, China: a single-centered, retrospective, observational study. Lancet Respir Med. 2020;8(5):475-481. doi:10.1016/S2213-2600(20)30079-5

7. Zhou F, Yu T, Du R, et al. Clinical course and risk factors for mortality of adult inpatients with COVID-19 in Wuhan, China: a retrospective cohort study. Lancet. 2020;395:1054-1062. doi:10.1016/S0140-6736(20)30566-3

8. Wu C, Chen X, Cai Y, et al. Risk factors associated with acute respiratory distress syndrome and death in patients with coronavirus disease 2019 pneumonia in Wuhan, China. JAMA Intern Med. 2020;180(7):934-943. doi:10.1001/jamainternmed.2020.0994

9. Van Paassen J, Vos JS, Hoekstra EM, Neumann KMI, Boot PC, Arbous SM. Corticosteroid use in COVID-19 patients: a systematic review and meta-analysis on clinical outcomes. Crit Care. 2020;24:696. doi:10.1186/s13054-020-03400-9

10. Ruan SY, Lin HH, Huang CT, Kuo PH, Wu HD, Yu CJ. Exploring the heterogeneity of effects of corticosteroids on acute respiratory distress syndrome: a systematic review and metaanalysis. Crit Care. 2014;18:R63. doi:10.1186/cc13819

11. World Health Organization. Corticosteroids for COVID-19. Living guidance. Available from: WHO/2019-nCoV/Corticosteroids/2020.1. Accessed September 2, 2020.

12. Sun S, Liu D, Zhang H, Zhang X, Wan B. Effect of different doses and time-courses of corticosteroid treatment in patients with acute respiratory distress syndrome: a meta-analysis. Exp Ther Med. 2019;18:4637-4644. doi:10.3892/etm.2019.8167

13. Bösmüller H, Matter M, Fend F, et al. The pulmonary pathology of COVID-19. Virchows Archiv. 2021;478:137-150. doi:10.1007/ s00428-021-03053-1

14. Shi H, Han X, Zheng C. Evolution of CT manifestations in a patient recovered from 2019 novel coronavirus (2019-nCoV) pneumonia in Wuhan, China. Radiology. 2020;295:200269. doi:10.1148/ radiol.2020200269.
15. Kooraki S, Hosseiny M, Myers L, Gholamrezanezhad A. Coronavirus (COVID-19) outbreak: what the department of radiology should know. $J$ Am Coll Radiol. 2020;17(4):447-451. doi:10.1016/j. jacr.2020.02.008

16. World Health Organization. Clinical management of severe acute respiratory infection when novel coronavirus (2019-nCov) infection is suspected: interim guidance. World Health Organization; 2020. Available from: https://apps:who.int/iris/handie/10665/330893. Accessed January 28, 2020.

17. Meduri GU, Siemieniuk RAC, Ness RA, Seyler SJ. Prolonged low-dose methylprednisolone treatment is highly effective in reducing duration of mechanical ventilation and mortality in patients with ARDS. J Intensive Care. 2018;6:53. doi:10.1186/s40560-018-0321-9

18. Sterne JAC, Murthy S, Diaz JV, et al. Association between administration of systemic corticosteroids and mortality among critically ill patients with COVID-19: a meta-analysis. JAMA. 2020;324 (13):1330-1341. doi:10.1001/jama.2020.17023

19. Li H, Yang SG, Gu L, et al. National Influenza A(H1N1)pdm09 clinical investigation group of China. Effect of low-to-moderatedose corticosteroids on mortality of hospitalized adolescents and adults with influenza A(H1N1)pdm09 viral pneumonia. Influenza Other Respir Viruses. 2017;11(4):345-354. doi:10.1111/irv.12456

20. Fadel R, Morrison AR, Vahia A, et al. Early short course corticosteroids in hospitalized patients with COVID-19. Clin Infect Dis. 2020;71(16):2114-2120. doi:10.1093/cid/ciaa601.

21. Fernández-Cruz A, Ruiz-Antorán B, Muñoz-Gómez A, et al. A retrospective controlled cohort study of the impact of glucocorticoid treatment in SARS-CoV-2 infection mortality. Antimicrob Agents Chemother. 2020;64:9. doi:10.1128/AAC.01168-20

22. Nelson BC, Laracy J, Shoucri S, et al. Clinical outcomes associated with methylprednisolone in mechanically ventilated patients with COVID-19. Clin Infect Dis. 2020.

23. Dequin PF, Heming N, Meziani F, et al. Effect of hydrocortisone on 21-day mortality or respiratory support among critically ill patients with COVID-19: a randomized clinical trial. JAMA. 2020;324 (13):1-9. doi:10.1001/jama.2020.16761

24. Liu J, Zheng X, Huang Y, et al. Successful use of methylprednisolone for treating severe COVID-19. J Allergy Clin Immunol. 2020;146 (2):325-327. doi:10.1016/j.jaci.2020.05.021

25. Fang X, Mei Q, Yang T, et al. Low-dose corticosteroid therapy does not delay viral clearance in patients with COVID-19. J Infect. 2020;81(1):147-178. doi:10.1016/j.jinf.2020.03.039

26. Zhou G, Zhao Q. Perspectives on therapeutic neutralizing antibodies against the novel coronavirus SARS-CoV-2. Int J Biol Sci. 2020;16 (10):1718-1723. doi:10.7150/ijbs.45123
Infection and Drug Resistance

\section{Publish your work in this journal}

Infection and Drug Resistance is an international, peer-reviewed openaccess journal that focuses on the optimal treatment of infection (bacterial, fungal and viral) and the development and institution of preventive strategies to minimize the development and spread of resistance. The journal is specifically concerned with the epidemiology of antibiotic resistance and the mechanisms of resistance development and diffusion in both hospitals and the community. The manuscript management system is completely online and includes a very quick and fair peerreview system, which is all easy to use. Visit http://www.dovepress.com/ testimonials.php to read real quotes from published authors. 